\title{
Role of TIM-4 in exosome-dependent entry of HIV-I into human immune cells
}

\author{
This article was published in the following Dove Press journal: \\ International Journal of Nanomedicine \\ 6 July 2017 \\ Number of times this article has been viewed
}

\author{
Brian Sims ${ }^{1-3, *}$ \\ Anitra L Farrow ${ }^{4, *}$ \\ Sparkle D Williams ${ }^{1,2}$ \\ Anju Bansal ${ }^{4}$ \\ Alexandre \\ Krendelchtchikov ${ }^{1,2,4}$ \\ Linlin $\mathrm{Gu}^{5}$ \\ Qiana L Matthews s.4,6 $^{3}$ \\ 'Division of Neonatology, Department \\ of Pediatrics, ${ }^{2}$ Department of Cell, \\ Developmental and Integrative \\ Biology, ${ }^{3}$ Center for AIDS Research, \\ ${ }^{4}$ Division of Infectious Diseases, \\ ${ }^{5}$ Division of Pulmonary, Allergy and \\ Critical Care Medicine, Department \\ of Medicine, University of Alabama \\ at Birmingham, Birmingham, \\ ${ }^{6}$ Microbiology Program, Department \\ of Biological Sciences, College of \\ Science, Technology, Engineering \\ and Mathematics, Alabama State \\ University, Montgomery, AL, USA \\ *These authors contributed equally \\ to this work
}

\begin{abstract}
Exosomes, 30-200 nm nanostructures secreted from donor cells and internalized by recipient cells, can play an important role in the cellular entry of some viruses. These microvesicles are actively secreted into various body fluids, including blood, urine, saliva, cerebrospinal fluid, and breast milk. We successfully isolated exosomes from human breast milk and plasma. The size and concentration of purified exosomes were measured by nanoparticle tracking, while Western blotting confirmed the presence of the exosomal-associated proteins CD9 and CD63, clathrin, and $\mathrm{T}$ cell immunoglobulin and mucin proteins (TIMs). Through viral infection assays, we determined that HIV-1 utilizes an exosome-dependent mechanism for entry into human immune cells. The virus contains high amounts of phosphatidylserine (PtdSer) and may bind PtdSer receptors, such as TIMs. This mechanism is supported by our findings that exosomes from multiple sources increased HIV-1 entry into T cells and macrophages, and viral entry was potently blocked with anti-TIM-4 antibodies.
\end{abstract}

Keywords: exosomes, HIV-1, T cell immunoglobulin and mucin proteins, phosphatidylserine, nanoparticle tracking analysis

\section{Introduction}

HIV-1 is a well-studied enveloped retrovirus that exploits primary and secondary cellular receptors to gain entry into host cells, which requires fusion interactions of the host receptor and viral ligands. These classical receptors include CD4 and the chemokine receptors CCR5 and CXCR4. Intriguingly, HIV-1 particles have been detected in cells that lack these receptors, suggesting the existence of a non-traditional pathway by which HIV-1 can gain cellular entry using unique molecules that enhance infection. ${ }^{1-4}$

One important feature of HIV-1 is its envelope, which it acquires upon exiting the host cell. The envelope gives HIV-1 a barrier that shields the virus from the immune system due to lipids and proteins derived from the target cell's membrane with major roles in HIV-1's pathogenicity. ${ }^{5}$ Although the envelope's proteins are more studied than its phospholipids, one major phospholipid of interest is phosphatidylserine (PtdSer) ${ }^{6}$ whose roles may include functioning as a cofactor for viral fusion with the cell, promoting cell-cell interactions, and acting as a target for specific binding proteins. ${ }^{7}$

PtdSer receptors facilitate apoptotic mimicry, a normal cellular mechanism that viruses exploit to gain entry into the cell. ${ }^{8}$ Because HIV-1 is rich in PtdSer, the virus likely has affinity for these receptors, such as human $\mathrm{T}$ cell immunoglobulin and mucin (TIM) protein. Human TIM proteins (TIM-1, TIM-3, and TIM-4) may have very important roles in immunological responses, such as inflammation and oral tolerance, ${ }^{9}$ and act as a receptor for PtdSer. ${ }^{10}$ Many enveloped viruses use TIM proteins to augment
Correspondence: Qiana L Matthews Department of Biological Sciences, Alabama State University, Montgomery, AL 36I04, USA

Tel +I 3342298449

Email qmatthews@alasu.edu 
viral entry, ${ }^{11-13}$ including West Nile virus, Ebola virus, and dengue virus, via exposed PtdSer molecules on the surface of the virion. ${ }^{11,14}$

We demonstrated in our previous work that TIM-4 in primary mouse neural stem cell (NSC)-derived exosomes participates in the cellular entry of adenovirus, a nonenveloped virus. ${ }^{15}$ Treatment with anti-TIM-4 antibody significantly blocked exosome-mediated adenovirus entry. Exosomes are 30-200 $\mathrm{nm}$ nanostructures secreted from donor cells into various body fluids ${ }^{16,17}$ and internalized by recipient cells. Exosomes are routinely released at the plasma membranes of different types of cells, facilitate intercellular communication, ${ }^{17,18}$ and mediate adaptive immune responses to pathogens and tumors by transferring soluble factors, proteins, mRNA, and microRNAs to recipient cells. ${ }^{17,19}$ Feng et $\mathrm{al}^{20}$ determined that TIM-4 is involved in the uptake of exosomes and that they enter cells via phagocytosis.

Here, we demonstrate that HIV-1 entry into human immune cells is enhanced by exosome-mediated trafficking and mediated partially through TIM-4.

\section{Methods \\ Cell culture}

Human $\mathrm{CD}^{+}$lymphoblastoid $\mathrm{T}$ cell line (line A3R5.7) was a gift from the UAB CFAR Virology core. These cells were commercially received from the NIH AIDS Research and Reference Reagent Program and subsequently genetically modified. A3R5.7 cells were maintained in RPMI 1640 medium supplemented with $10 \%$ heat-inactivated, exosome-free fetal bovine serum, $2 \mathrm{mM}$ L-glutamine, penicillin $(100 \mathrm{U} / \mathrm{mL})$, streptomycin $(100 \mu \mathrm{g} / \mathrm{mL})$ (Thermo Fisher Scientific, Waltham, MA, USA), and $1 \mathrm{mg} / \mathrm{mL}$ geneticin (G418; Thermo Fisher Scientific). Human monocytic cells (line THP2574) were maintained in similar medium but without geneticin. ${ }^{21,22}$ All other cell lines were purchased from American Type Culture Collection.

\section{Exosome purification} Isolation of NSC-derived exosomes

Mouse cortical NSCs were cultured in serum-free culture medium for exosome extraction. In brief, cells were centrifuged at 5,000 rpm for $10 \mathrm{~min}$ at $4^{\circ} \mathrm{C}$ using a Sorvall RT600 centrifuge with a swinging bucket rotor (Thermo Fisher Scientific). The supernatant was clarified by filtration through a $0.22 \mu \mathrm{m}$ filter and centrifuged at $32,000 \mathrm{rpm}$ for $70 \mathrm{~min}$ at $4^{\circ} \mathrm{C}$ using an SW41T1 swinging rotor in a Beckman Coulter
(Brea, CA, USA) Optima L-70K ultracentrifuge for exosome collection. ${ }^{15,19}$ Exosomes were resuspended in $120-450 \mu \mathrm{L}$ sterile phosphate-buffered saline (PBS) and then quantified by Bradford protein quantitation method.

\section{Isolation of human lung cell carcinoma-derived exosomes}

Cell line A549 was grown in RPMI 1640 complete medium containing exosome-free fetal bovine serum to $\sim 80 \%$ confluency. The cell culture medium was centrifuged at 5,000 rpm for $10 \mathrm{~min}$ at $4^{\circ} \mathrm{C}$ and clarified by filtration through a $0.22 \mu \mathrm{m}$ filter. The filtrate was then centrifuged at $32,000 \mathrm{rpm}$ for $70 \mathrm{~min}$ to collect exosomes, ${ }^{15,19}$ which were resuspended in $120-450 \mu \mathrm{L}$ sterile PBS.

\section{Isolation of breast milk-derived exosomes}

Breast milk samples were collected from samples prior to being discarded from healthy human donors and centrifuged twice at 3,500 rpm for $10 \mathrm{~min}$ at $4^{\circ} \mathrm{C}$. The fat layer was aspirated and the supernatant transferred to a new tube. A third spin was performed at 5,000 rpm for $30 \mathrm{~min}$ at $4^{\circ} \mathrm{C}$, after which the remaining fat was aspirated and the supernatant transferred to a new tube. Breast milk was then filtered with a $0.22 \mu \mathrm{m}$ filter, transfered into ultracentrifuge tube and then the tube volume was adjusted with PBS prior to an ultracentrifugation spin at $32,000 \mathrm{rpm}$ for $70 \mathrm{~min}$ at $4^{\circ} \mathrm{C}$. The pellet was collected and resuspended in 120-450 $\mu \mathrm{L}$ sterile PBS.

\section{Isolation of human plasma-derived exosomes}

Plasma was collected from whole blood of human donors into tubes containing ethylenediaminetetraacetic acid (EDTA) and processed as described by Konadu et $\mathrm{al}^{23}$ with some modifications. Whole-blood samples were centrifuged at $3,500 \mathrm{rpm}$ for $10 \mathrm{~min}$ at $4^{\circ} \mathrm{C}$. If the samples contained a high lipid content after the low-speed centrifugation (evidenced by color), they were incubated for $2 \mathrm{~h}$ at $4^{\circ} \mathrm{C}$, and the precipitated fat was removed by centrifugation at 5,000 rpm for $10 \mathrm{~min}$ at $4^{\circ} \mathrm{C}$. The supernatants were then filtered through a $0.22 \mu \mathrm{m}$ filter and ultracentrifuged for $30 \mathrm{~min}$ at $32,000 \mathrm{rpm}$ at $4^{\circ} \mathrm{C}$. The pellet was collected by centrifuging the samples at $27,000 \mathrm{rpm}$ for $2 \mathrm{~h}$ at $4^{\circ} \mathrm{C}$. The resulting pellet was resuspended in $1 \mathrm{~mL}$ PBS, loaded on to OptiPrep velocity gradients, and subjected to flotation centrifugation at 27,000 rpm for $2 \mathrm{~h}$. Fractions with peak exosome content (fractions 2 and 3 ) were pooled, diluted with PBS, and ultracentrifuged for $2 \mathrm{~h}$ at 32,000 rpm. The exosome pellet was resuspended in $120 \mu \mathrm{L}$ PBS. 


\section{SDS-PAGE and Western blot analyses of exosome-associated proteins}

To analyze proteins associated with exosomes, exosomes were mixed with loading buffer (1:1), boiled, and resolved on a $4 \%-12 \%$ Bis-Tris gel, followed by transfer and blocking on a polyvinylidene difluoride membrane. Blotting was performed with four different primary antibodies: anti-clathrin monoclonal antibodies (1:1,000; BD Biosciences, San Jose, CA, USA), anti-CD9 (1:1,000; System Biosciences, Inc., Palo Alto, CA, USA), anti-CD63 (1:1,000; System Biosciences, Inc.), and anti-TIM-4 (1:1,000; Sino Biological, Inc., Beijing, China) antibodies. Then incubation with secondary antibodies was performed using either horseradish peroxidase (HRP)-conjugated goat anti-mouse (1:2,000; Dako Denmark A/S, Glostrup, Denmark) or anti-rabbit (1:20,000; System Biosciences, Inc.) antibodies. Proteins were detected using an enhanced chemiluminescence kit (ELC Western Blotting Substrate Pierce/Thermo Fisher Scientific) and a Bio-Rad ChemiDoc XRS system (Bio-Rad Laboratories, Hercules, CA, USA).

\section{HIV-I infection of human cell lines}

HIV-1 experiments were conducted using an infectious molecular clone (NL-LucR.T2A-YU2.ecto [YU-2]) engineered to express Renilla luciferase (LucR) and ENV from the YU-2 virus strain, which was derived from the postmortem brain of a patient with HIV-associated neurocognitive disorder (HAND).

A3R5.7 cells were seeded on 96-well plates at a density of $1 \times 10^{5}$ cells/well with the addition of $5 \mu \mathrm{g} / \mathrm{mL}$ diethylaminoethyl-dextran. ${ }^{24}$ Exosomes derived from NSC, A549, breast milk, and plasma were incubated, respectively, with YU-2 at a multiplicity of infection (MOI) of 0.002 for $1 \mathrm{~h}$ at $37^{\circ} \mathrm{C}$ in $5 \% \mathrm{CO}_{2},{ }^{25}$ and then $\mathrm{HIV}-1$ /exosome mixture was co-incubated with the cells for $72 \mathrm{~h}$ at $37^{\circ} \mathrm{C}$ in $5 \% \mathrm{CO}_{2}$. LucR activity was determined using the Renilla Luciferase Assay System (Promega Corporation, Fitchburg, WI, USA). Relative luminescence units (RLUs) were measured in triplicate on a Victor X light luminescence counter (PerkinElmer Inc, Waltham, MA, USA) with an exposure time of $0.1 \mathrm{~s} /$ well.

THP2574 cells $\left(1 \times 10^{4}\right.$ cells/well $)$ were classically differentiated into macrophages with $1 \mathrm{ng} / \mathrm{mL}$ phorbol 12-myristate 13-acetate for $96 \mathrm{~h}$. Clone YU-2 with an MOI of 0.18 was incubated with exosomes for $1 \mathrm{~h}$ at $37^{\circ} \mathrm{C}$ in $5 \% \mathrm{CO}_{2}$. The $\mathrm{HIV}-1 /$ exosome mixture was co-incubated with the cells for $72 \mathrm{~h}$ at $37^{\circ} \mathrm{C}$ in $5 \% \mathrm{CO}_{2}$, and LucR activity was measured in triplicate as described earlier.
Amounts of exosomes and viral MOIs used for each cell line were determined experimentally. The following quantities of exosomes, which would saturate all HIV-1 virions, were used for viral entry experiments: $0.1 \mu \mathrm{g}$ NSCderived exosomes, $0.035 \mu \mathrm{g}$ breast milk-derived exosomes, $0.05 \mu \mathrm{g}$ plasma cell-derived exosomes, and $0.1 \mu \mathrm{g}$ A549derived exosomes.

\section{Blocking of HIV-I infection}

A protocol similar to HIV-1 infection was performed but with addition of $0.2 \mu \mathrm{g} /$ well anti-mouse TIM-4 or anti-human TIM-4 (Sino Biological, Inc.) to the YU-2/exosome/cell incubation or with YU-2 only as a control.

\section{Determining exosome size and concentration}

We used nanoparticle tracking analysis (NTA) using the NanoSight LM10 (Malvern Instruments, Inc., Malvern, UK) and NTA v2.0 software to characterize breast milk- and plasmaderived exosomes. All data were collected using five frames and in triplicate. Samples were diluted 1:1,000 prior to tracking, which led to particle sizes of $10^{-7}-10^{-9} \mathrm{~m}$. Mean values were recorded and analyzed for each given reading frame.

\section{Human study participants}

The study was approved by the Institutional Review Board (IRB) for the Protection of Human Subjects in Research at the University of Alabama at Birmingham (UAB) in accordance with approved guidelines and protocol. Breast milk was collected from samples prior to being discarded at the UAB Regional Newborn Intensive Care Unit with expedited IRB approval. Blood donors provided written informed consent prior to donation.

\section{Statistical analysis}

One-way analysis of variance with a post hoc Tukey's test was performed on obtained data points, and results are presented as mean \pm standard error of the mean (SEM). Statistical significance was defined as $P \leq 0.05$.

\section{Results \\ Isolation and characterization of exosomes}

Exosomes were isolated and characterized for exosomal markers, such as CD9 and CD63, as described in our previous study. ${ }^{15}$ For these studies, we isolated exosomes from two cell lines, NSC and human lung carcinoma (A549). We also 
isolated exosomes from human breast milk and human plasma using published methods. ${ }^{15,23}$ To confirm successful exosome isolation, we performed a series of SDS-PAGE and Western blot analyses to examine expression of well-known exosomal proteins (Figure 1A and B). Specifically, breast milk exosomes incubated with anti-clathrin and-CD9 antibodies yielded protein bands at $180 \mathrm{kDa}$ and $28 \mathrm{kDa}$, respectively (Figure 1A1 and A2). Similarly, analysis of human plasma exosomes incubated with anti-CD9 and -CD63 antibodies confirmed their presence as well (Figure 1B1 and B2). Moreover, Western blotting detected TIM-4 associated with human plasma exosomes (Figure 1C), which we had previously found on NSC-derived exosomes. ${ }^{15}$

We used NTA to validate our exosome population from human biological samples (Figure 1D and 1E). Human plasma exosomes (Figure 1D) have a mean diameter size of $180 \mathrm{~nm} \pm 64.1 \mathrm{~nm}$ and mean concentration of $1.68 \times 10^{9} \pm 4.00 \times 10^{7}$ particles/mL. Human breast milk-derived exosomes (Figure 1E) have a mean size of $116.2 \mathrm{~nm} \pm 56.2 \mathrm{~nm}$ and mean concentration of $3.42 \times 10^{6} \pm 3.91 \times 10^{5}$ particles $/ \mathrm{mL}$.

\section{NSC- and A549 cell-derived exosomes augment HIV-I entry into human \\ T lymphoblastoid and differentiated macrophage cell lines}

We previously showed that mouse NSC-derived exosomes mediate adenoviral entry independent of the Coxsackie virus and adenovirus receptor ${ }^{15}$ and that this entry is blocked by anti-TIM-4 antibody. As proof of principle, we used mouse NSC-derived exosomes in this study to determine if they could facilitate cellular entry of an HIV-1 variant derived from a patient diagnosed with HAND.

The NSC-derived exosomes represent an orthotropic mechanism for brain-specific exosome-mediated HIV-1 entry in vitro, so we investigated if mouse NSC-derived exosomes significantly enhance HIV-1 entry and induce viral gene expression as indicated by LucR activity. To determine the impact of exogenous exosomes on HIV-1 entry and subsequent gene expression, we performed a series of viral infection experiments using exosomes only (as mock infection),
A
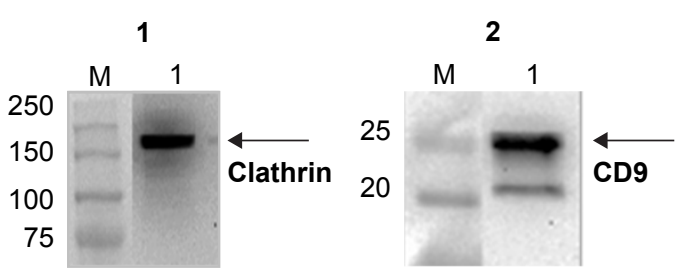

B
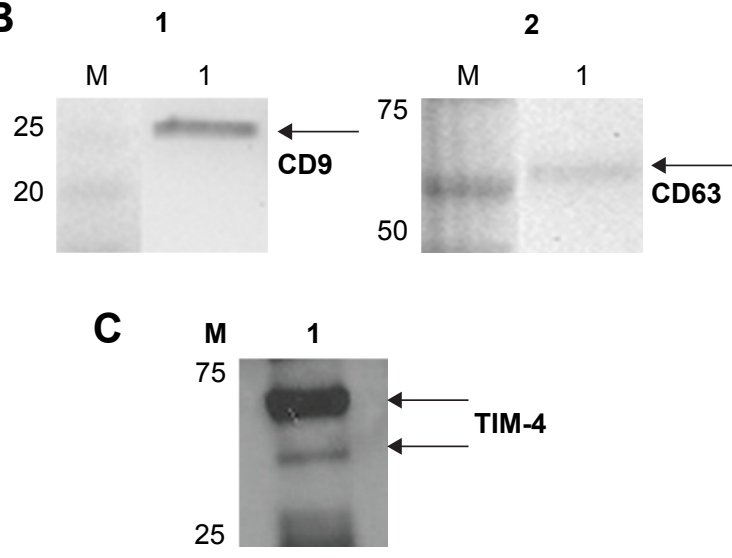

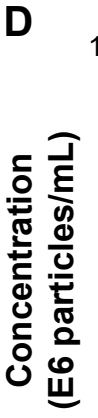

$\mathbf{E}$

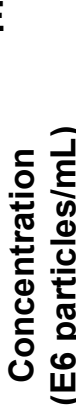

154.43

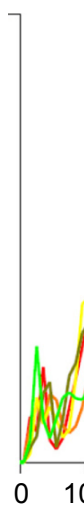

Mean: $180.8 \pm 64.1 \mathrm{~nm}$ Concentration: $1.68 \times 10^{9} \pm$ $4.00 \times 10^{7}$ particles $/ \mathrm{mL}$
Human plasma

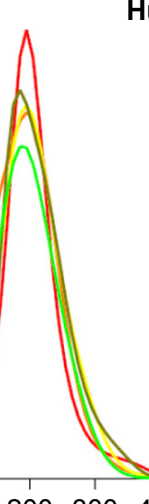

$\begin{array}{lllll}500 & 600 & 7008009001,000\end{array}$

Size (nm)

Human breast milk
Mean: $116.6 \pm 56.2 \mathrm{~nm}$

Concentration: $3.42 \times 10^{6} \pm$ $3.91 \times 10^{5}$ particles $/ \mathrm{mL}$

Figure I Western blot and NTA validation of exosomal samples.

Notes: Western blots of (A) breast milk exosomes (60 $\mu \mathrm{g} /$ lane) [(AI) clathrin and (A2) CD9] and (B, C) plasma exosomes (25 $\mu \mathrm{g} /$ lane) [(BI) CD9, (B2) CD63], (C) TIM-4. Arrows indicate proteins of interest. (D, E) NTA-generated size and concentration plots for (D) human plasma- and (E) human breast milk-derived exosomes. Abbreviations: NTA, nanoparticle tracking analysis; TIM, T cell immunoglobulin and mucin. 
YU-2 only, and exosomes with YU-2 only or with YU-2 and added anti-TIM-4 antibody. TIM-4-blocking experiments were based on previously published experimental dose titrations. ${ }^{15}$ The above mentioned combinations were administered to either the T lymphoblastoid cell line A3R5.7 or the macrophage-like cell line THP2574.

YU-2 alone infected A3R5.7 cells and induced viral gene expression, which was measured at $\sim 200,000$ RLU. Co-incubation of YU-2 with $0.1 \mu \mathrm{g}$ NSC-derived exosomes increased the number of RLU significantly $(P \leq 0.0001)$ compared to YU-2 only. This increased exosome-mediated
HIV-1 gene expression was reversed when TIM-4 blocking was performed via anti-TIM-4 antibodies $(P \leq 0.0001)$ (Figure 2A).

In THP2574 macrophages, YU-2 alone infected the cells and yielded $\sim 600,000$ RLU (Figure 2B). Co-incubation of YU-2 with NSC-derived exosomes significantly increased the number of RLU ( $P=0.0221)$ compared to YU-2 only. Administration of a combination of NSC-derived exosomes, YU-2, and anti-TIM-4 led to a significant decrease in RLU compared to the administration of YU-2 only $(P=0.001)$ and NSC-derived exosomes with YU-2 $(P \leq 0.0001)$. The addition

B

A3R5.7

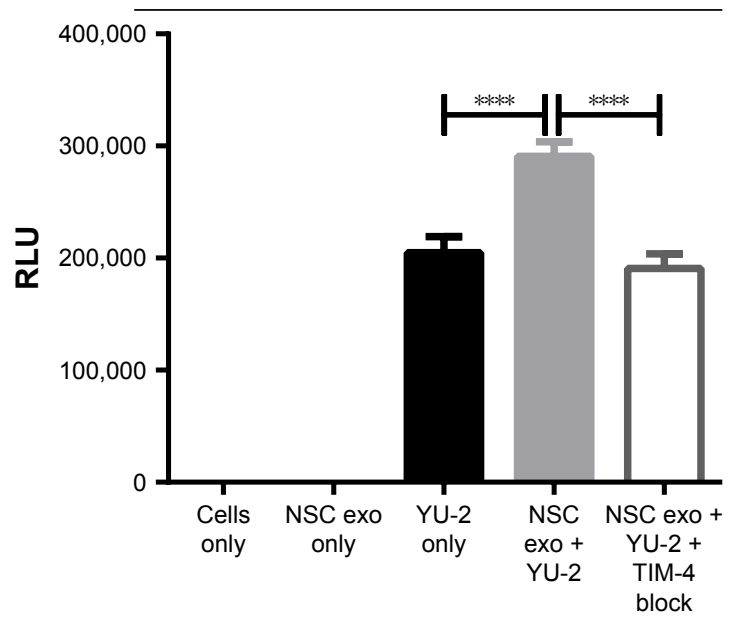

+Dextran

C

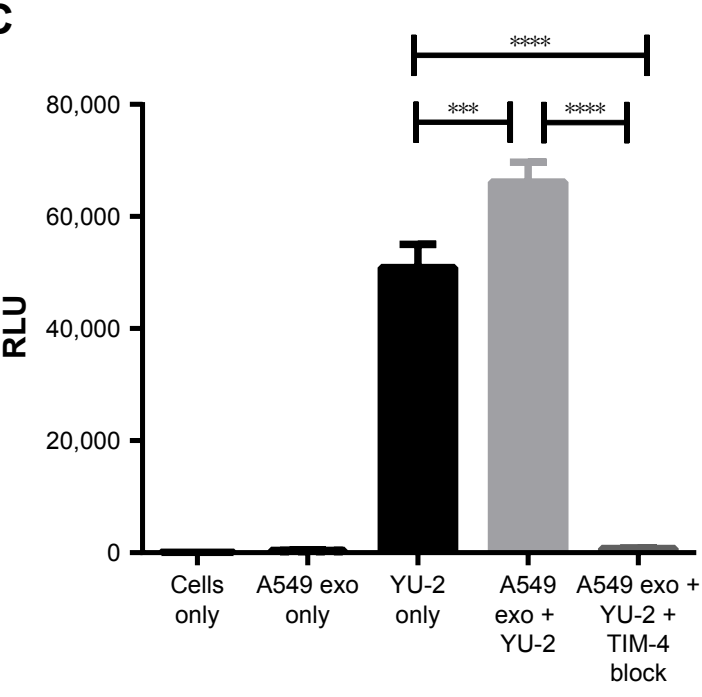

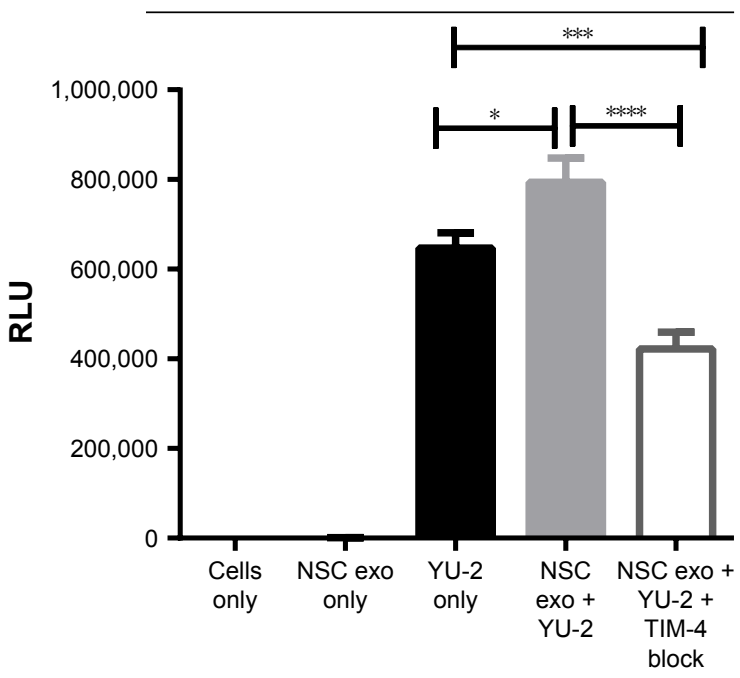

D

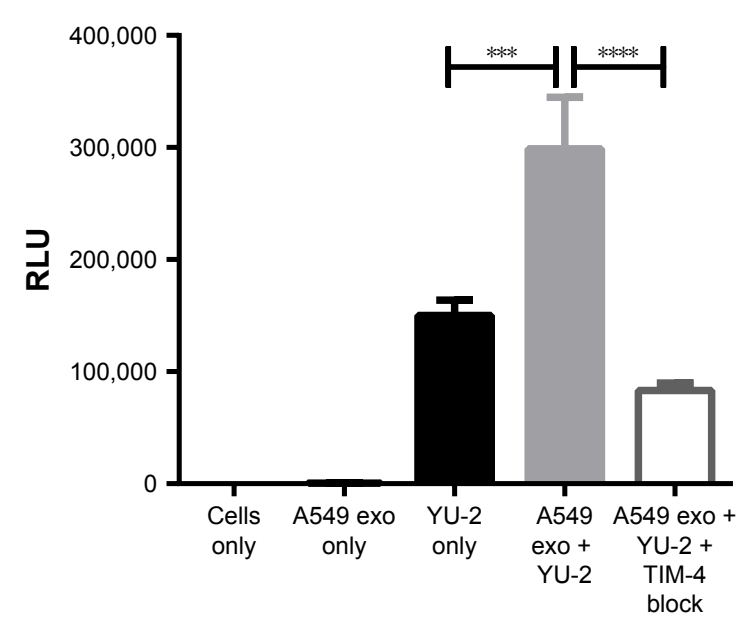

+Dextran

Figure 2 NSC- and A549-derived exosomes significantly enhance HIV-I entry into human immune cell lines.

Notes: (A, C) YU-2 virus entry into A3R5.7 cells was evaluated in the presence or absence of (A) NSC-derived exosomes (0.I $\mu \mathrm{g})$ or $(\mathbf{C})$ A549-dervied exosomes $(0.1 \mu \mathrm{g})$. (B, D) The differentiated THP2574 cell line was used for entry experiments with YU-2 in the presence or absence of (B) NSC-derived exosomes (0.I $\mu \mathrm{g})$ or (D) A549-derived exosomes $(0.1 \mu \mathrm{g})$. Virus entry was also evaluated in the presence of exosomes and anti-TIM-4 antibody. Viral gene expression in all control and treatment groups was assessed by Renilla luciferase activity at $72 \mathrm{~h}$ post-infection. Data represent 12 independent experiments. Significant differences between treatment groups were determined by one-way ANOVA $* P<0.05$, *** $P<0.001$, $* * * * P<0.0001$. YU-2, (NL-LucR.T2A-YU2.ecto) engineered to express Renilla luciferase (LucR) and ENV from the YU-2 virus strain.

Abbreviations: NSC, neural stem cell; TIM, T cell immunoglobulin and mucin; ANOVA, analysis of variance; RLU, relative luminescence unit, exo, exosomes. 
of anti-TIM-4 antibody significantly diminished viral gene expression, further illustrating the specificity of TIM-4/ exosome interactions in multiple human cell types.

HIV-1-infected patients experience increased incidence of cancer, especially non-AIDS-defining cancers (NADCs), such as lung cancer. To investigate if cancer cell-derived exosomes can fuel HIV-1 pathogenesis in A3R5.7 and THP2574 cells, we used human lung carcinoma cells (A549)-derived exosomes. Figure $2 \mathrm{C}$ shows that co-incubation of YU-2 with $0.1 \mu \mathrm{g}$ A549 cell-derived exosomes significantly increased HIV-1 entry in A3R5.7 cells $(P=0.0004)$ compared to the YU-2-only control. Anti-TIM-4 antibodies significantly limited exosome-mediated HIV-1 entry into A3R5.7 $(P \leq 0.0000)$ and THP2574 cells $(P \leq 0.0001)$ and subsequent viral gene expression. We also validated the ability of human A549derived exosomes to significantly enhance HIV-1 entry into macrophages $(P=0.0001$; Figure 2D).

\section{Breast milk- and plasma-derived exosomes augment HIV-I entry into human target cell lines}

A noteworthy proportion of mother-to-child transmission (MTCT) cases of HIV-1 occurs during breastfeeding in situations where replacement feeding is unsafe or impractical. ${ }^{26}$ Breast milk-derived exosomes enhanced YU-2 entry into A3R5.7 cells, but not significantly, compared to YU-2 alone (Figure 3A). However, anti-TIM-4 antibodies notably blocked YU-2 entry ( $P \leq 0.0001)$. In contrast, we observed that breast milk-derived exosomes significantly enhanced YU-2 entry into THP2574 macrophages $(P=0.008)$ compared to YU-2 alone, while addition of anti-TIM-4 antibody decreased YU-2 entry into the cells (Figure 3B).

Because HIV-1 transmission also frequently occurs through blood exchange, we also evaluated the ability of plasma-derived exosomes to promote HIV-1 cellular entry. We validated the ability of the plasma exosomes to enhance YU-2 entry into human T cell line A3R5.7. Co-incubation of YU-2 with plasma-derived exosomes significantly enhanced YU-2 entry into AR35.7 cells $(P=0.001)$ compared to YU-2 only (Figure 3C), which was subsequently blocked by anti-TIM-4 antibodies. Figure 3D shows that co-incubation of HIV-1 with plasma exosomes also increased HIV-1 entry into THP2574 cells ( $P \leq 0.0001)$, and its entry was again significantly blocked by anti-TIM-4 antibodies $(P \leq 0.0001)$.

Because the HIV-1 envelope contains abundant PtdSer, we investigated the possibility of HIV-1 direct cellular entry via binding to cellular TIM-4. In a subset of HIV-1 entry experiments (Figure S1), we evaluated an additional control treatment of anti-TIM-4 antibodies and YU-2 only (no exosomes) to THP2574 cells. We observed similar viral gene expression levels between the YU-2-only and the TIM-4-blocking groups, suggesting that HIV-1 cannot directly enter human T cells via binding to cellular TIM-4.

\section{Discussion}

Growing evidence details the role of exosomes in viral pathogenesis. Exosomes are present in many body fluids, such as amniotic fluid, ascites fluid, breast milk, bronchoalveolar lavage, cerebrospinal fluid, plasma, saliva, semen, and urine, ${ }^{27-35}$ and we investigated HIV-1 interactions with exosomes from various sources. Retroviruses may have important similarities to exosomes and can exploit the exosome biogenesis pathway, which aids in viral dissemination. This mechanism, described in the Trojan exosome hypothesis, involves envelope- and receptor-independent viral entry. ${ }^{36,37}$

Exosomes inhibit or promote HIV-1 infections, depending on their cellular context. Blood-derived exosomes promote HIV-1 infection via CCR5/CXCR4, Gag, viral mRNA/ miRNA, TAR RNA, CD45/CD86, and tumor necrosis factor- $\alpha$ (TNF- $\alpha) ;{ }^{38-44}$ HIV-1 infection can be inhibited by the same exosomes via APOBEC3G, CD4, interferon (IFN)- $\alpha$, IFN- $\beta$, and various interleukins. ${ }^{45-50}$ Exosomes derived from breast milk or semen can also inhibit HIV-1 infection via IgA, IgG, mucin 1, and oligosaccharides, ${ }^{51-53}$ although semenderived exosomes only inhibit HIV-1 entry specifically via mucin $6 .{ }^{54}$ The effects of exosomes from other body fluids, such as urine, saliva, bronchoalveolar lavage, and cerebrospinal fluid, on HIV-1 entry are currently unexplored.

We characterized purified exosomes by SDS-PAGE, Western blotting, and NTA. In addition to confirming the presence of exosomal markers, we verified the presence of TIM-4 on exosomes derived from primary mouse NSCs and human plasma. Here, we evaluated a genetically modified HIV-1 variant of YU-2, a strain isolated from patients with HIV-associated dementia, thus representing an HIV-1 strain relevant for assessing central nervous system (CNS)-related investigations. ${ }^{25}$ The current paradigm of HIV-1 infection in the CNS involves monocyte- and macrophage-mediated entry via the CD4/CCR5 receptor. However, CD4- brain cells can also be infected with HIV-1 and can act as active HIV-1 reservoirs. One proposed alternative infection pathway involves Trojan exosomes, which may cross the blood-brain barrier or be released from cells within the CNS. Our first set of HIV-1 entry experiments involved NSC-derived exosomes and demonstrated that mouse NSC-derived exosomes enhanced YU-2 viral entry into human target cells. 
A

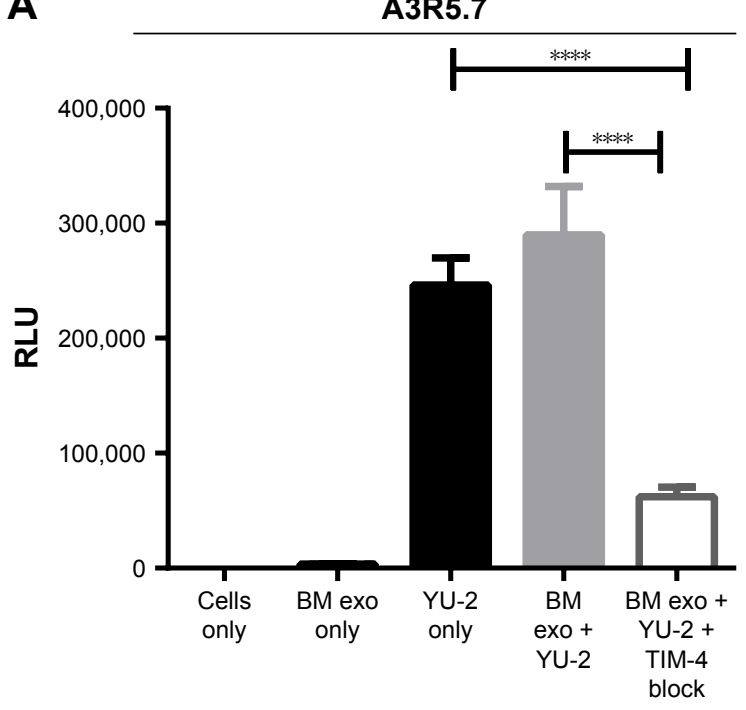

+Dextran

C

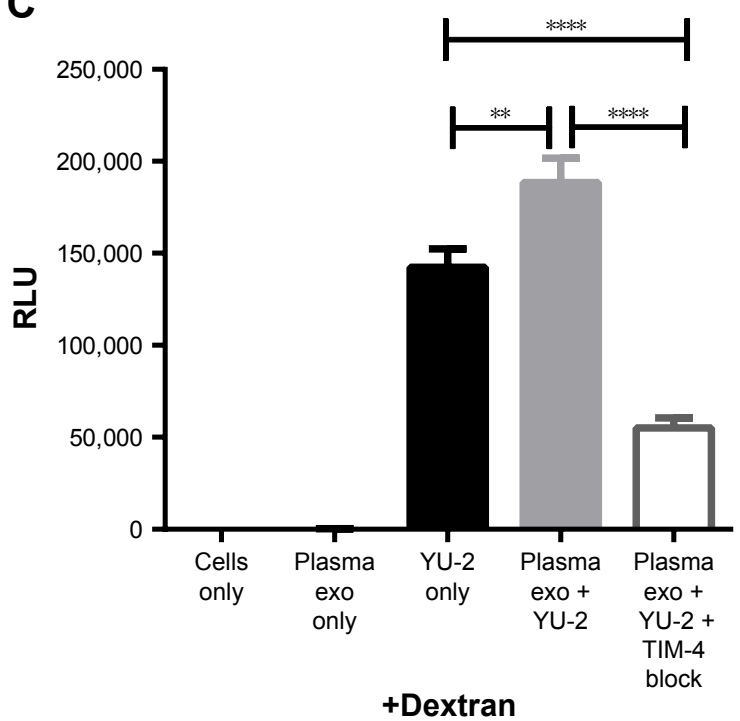

B

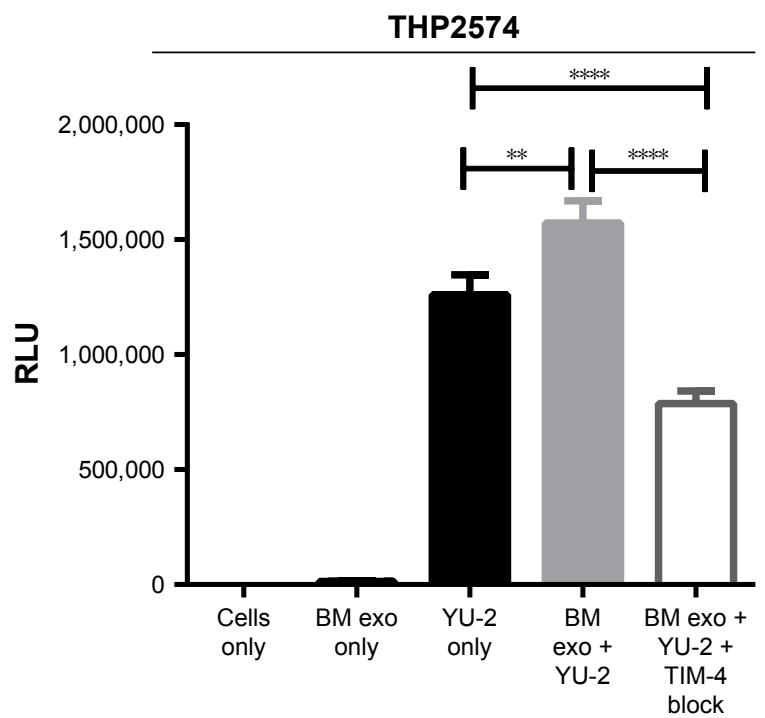

D 2,0

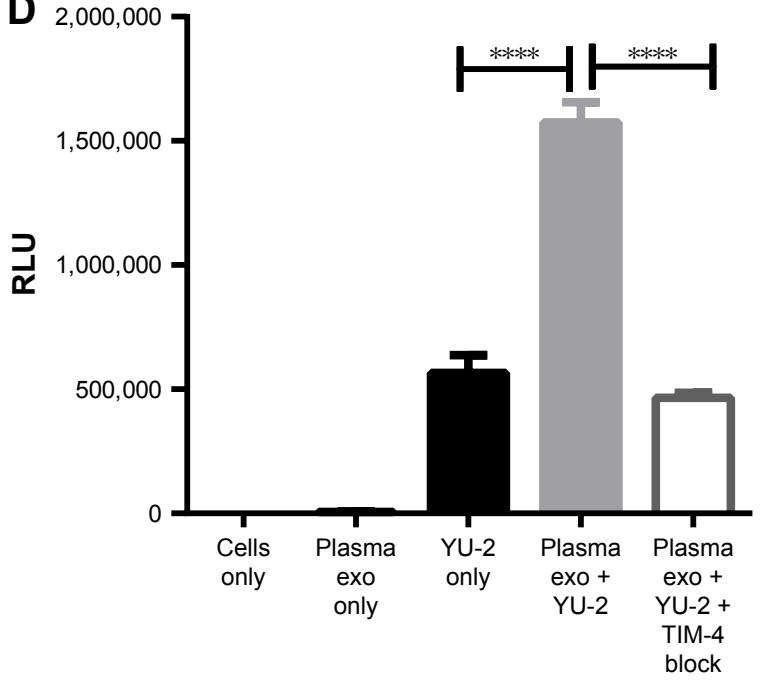

Figure 3 Breast milk- and plasma-derived exosomes enhance HIV-I entry into human immune cell lines.

Notes: (A, C) YU-2 virus entry into A3R5.7 cells was evaluated in the presence or absence of $(\mathbf{A})$ breast milk-derived exosomes $(0.035 \mu \mathrm{g})$ or $(\mathbf{C})$ plasma-derived exosomes $(0.05 \mu \mathrm{g})$. Virus entry was evaluated in the presence of exosomes and anti-TIM-4 antibodies. (B, D) The differentiated THP2574 cell line was used for entry experiments with YU-2 in the presence or absence of (B) breast milk-derived exosomes $(0.035 \mu \mathrm{g})$ or $(\mathbf{D})$ plasma-derived exosomes $(0.05 \mu \mathrm{g})$. Virus entry was also evaluated in the presence of exosomes and anti-TIM-4 antibody. Viral gene expression in all control and treatment groups was assessed by Renilla luciferase activity at $72 \mathrm{~h}$ post-infection. Data represent 12 independent experiments. Significant differences between treatment groups were determined by one-way ANOVA. ${ }^{* * P}<0.01$, ****P $<0.000 \mathrm{I}$. YU-2, (NL-LucR.T2A-YU2. ecto) engineered to express Renilla luciferase (LucR) and ENV from the YU-2 virus strain.

Abbreviations: TIM, T cell immunoglobulin and mucin; ANOVA, analysis of variance; RLU, relative luminescence unit; BM, breast milk; exo, exosomes.

This study expands on our previous finding that mouse NSC-derived exosomes promoted entry of adenovirus, a non-enveloped virus, into an adenovirus-deficient cell line. ${ }^{15}$ We also detected TIM-4 on the surface of the exosomes and found that the protein interacts with adenovirus type 5, leading us to hypothesize that exosomal TIM-4 may also play a role in HIV-1 trafficking.

Our proposed mechanism of HIV-1 entry involves interactions between PtdSer moieties on the virus' envelope and target cell receptors. This mechanism is supported by abundant PtdSer on the HIV-1 envelope, making them likely ligands of phospholipid-binding proteins, such as TIMs.${ }^{6}$ Moreover, these proteins have been observed in exosomes and can bind to HIV-1. Finally, we determined that when TIM-4 is blocked by anti-TIM-4 antibodies, interactions between HIV-1 and exosomes decrease, leading to reduced HIV-1 entry into human $\mathrm{T}$ lymphoblastoid and macrophage cell lines.

We also investigated the ability of lung carcinoma cellderived exosomes to enhance YU-2 entry into both human cell lines. Cancer cell-derived exosomes are involved in cancer metastasis, ${ }^{55}$ and pulmonary malignancies, including NADCs, which are a major cause of morbidity and mortality 
in HIV-infected individuals. ${ }^{56} \mathrm{HIV}$-associated factors appear to increase the risk of lung cancer and may adversely impact cancer treatment and outcomes in NADC patients. We speculate that cancer cell-derived exosomes, in addition to participating in cancer progression, may facilitate HIV-1 pathogenesis and dissemination to unlikely organ types.

MTCT accounts for $\sim 260,000$ new HIV-1 infections annually, with the majority of cases in sub-Saharan Africa, and one-third to one-half of these infections occur postpartum. ${ }^{57-59}$ Breast milk-mediated MTCT of HIV-1 remains an enigma, so identifying the ability of breast milk components that promote or inhibit HIV-1 MTCT could help limit the occurrence of postpartum HIV-1 transmission. Human breast milk contains many antibacterial and antiviral compounds, and breast milk-derived exosomes have been shown to inhibit HIV-1 infection. In this study, we evaluated the impact of breast milk-derived exosomes on HIV-1 entry and found that their co-incubation with YU-2 did enhance viral entry into the $\mathrm{T}$ cell line, although the enhancement was not statistically significant. However, TIM-4 blocking dramatically reduced YU-2 entry, indicating that multiple factors may impact exosome, HIV-1, and T cell interactions and necessitating further investigation. Alternatively, breast milk-derived exosomes significantly promoted HIV-1 entry into macrophages, and, like in $\mathrm{T}$ cells, viral entry was inhibited using anti-TIM-4 antibodies. We also evaluated the effect of plasma-derived exosomes on YU-2 entry into the two cell lines. These exosomes increased YU-2 entry more than any other exosome type, but viral entry was again blocked by addition of anti-TIM-4 antibodies. Thus, our findings suggest a direct relationship between HIV-1 entry and exosomes.

Exosome and anti-TIM-4 antibody concentrations were calculated for saturation of YU-2 viral particles in our infection experiments. Therefore, the incomplete inhibition of YU-2 entry into A3R5.7 cells co-incubated with NSCderived exosomes and anti-TIM-4 antibodies indicates that other TIMs or related proteins mediate exosome and viral entry in different cellular contexts. However, with the exosomes we evaluated, TIM-4 acts as the dominant mediator.

Our findings implicate exosomes as enhancers of HIV-1 viral entry into multiple human cell types. For future study, stringent profiling for identifying specific exosome-associated proteins (eg, TIM-1 or TIM-3) may explain why various types of exosomes differentially influence YU-2 entry into target cells and are affected by TIM-4 blocking in different ways. Although we found that exosomes generally increase HIV-1 entry into both T cells and macrophages, additional analyses with exosomes from HIV-1-infected patient samples will also improve our understanding of virus and exosome interactions and HIV-1 pathogenesis.

\section{Acknowledgments}

This work was supported by the American Association of Immunologists Careers in Immunology Fellowship Program (to AF), Gorgas Memorial Foundation Research Grant Award (QLM), National Institutes of Health grant \#5R01AI089337-04 (to QLM), and University of Alabama at Birmingham (UAB) Center for AIDS Research (CFAR), an NIH-funded program (P30 AI027767) made possible by the following institutes: NIAID, NCI, NICHD, NHLBI, NIDA, NIMH, NIA, NIDDK, NIGMS, FIC, and OAR. We are thankful to the scientific support from the Virology Core, which is part of the UAB CFAR P30-AI-27767. A3R5.7 and THP2574 cell lines were a generous gift from the UAB CFAR Virology Core. We are thankful to the High Resolution Imaging Facility Service Center who provided NTA. The High Resolution Imaging Facility is an institutional core at UAB supported by the Office of the Vice President of Research and Development and the following grants: Cancer Center Support Grant P30 CA013148 and Rheumatic Disease Core Center P30 AR048311. The funders had no role in the study design, data collection and analysis, decision to publish, or preparation of the manuscript.

\section{Disclosure}

The authors report no conflicts of interest in this work.

\section{References}

1. MacPherson JI, Dickerson JE, Pinney JW, Robertson DL. Patterns of HIV-1 protein interaction identify perturbed host-cellular subsystems. PLoS Comput Biol. 2010;6(7):1000863.

2. Franzosa EA, Xia Y. Structural principles within the human-virus protein-protein interaction network. Proc Natl Acad Sci U S A. 2011; 108(26):10538-10543.

3. Chan EY, Korth MJ, Katze MG. Decoding the multifaceted HIV-1 virushost interactome. J Biol. 2009;8(9):84.

4. Sarmady M, Dampier W, Tozeren A. HIV protein sequence hotspots for crosstalk with host hub proteins. PLoS One. 2011;6(8):15.

5. Huarte N, Carravilla P, Cruz A, et al. Functional organization of the HIV lipid envelope. Sci Rep. 2016;6:34190.

6. Aloia RC, Tian H, Jensen FC. Lipid composition and fluidity of the human immunodeficiency virus envelope and host cell plasma membranes. Proc Natl Acad Sci U S A. 1993;90(11):5181-5185.

7. Callahan MK, Popernack PM, Tsutsui S, Truong L, Schlegel RA, Henderson AJ. Phosphatidylserine on HIV envelope is a cofactor for infection of monocytic cells. J Immunol. 2003;170(9):4840-4845.

8. Morizono K, Chen IS. Role of phosphatidylserine receptors in enveloped virus infection. J Virol. 2014;88(8):4275-4290.

9. Kuchroo VK, Umetsu DT, DeKruyff RH, Freeman GJ. The TIM gene family: emerging roles in immunity and disease. Nat Rev Immunol. 2003; 3(6):454-462. 
10. Kane LP. T cell Ig and mucin domain proteins and immunity. J Immunol. 2010;184(6):2743-2749.

11. Jemielity S, Wang JJ, Chan YK, et al. TIM-family proteins promote infection of multiple enveloped viruses through virion-associated phosphatidylserine. PLoS Pathog. 2013;9(3):28.

12. Moller-Tank S, Kondratowicz AS, Davey RA, Rennert PD, Maury W. Role of the phosphatidylserine receptor TIM-1 in enveloped-virus entry. J Virol. 2013;87(15):8327-8341.

13. Kaplan G, Totsuka A, Thompson P, Akatsuka T, Moritsugu Y, Feinstone SM. Identification of a surface glycoprotein on African green monkey kidney cells as a receptor for hepatitis A virus. EMBOJ. 1996; 15(16):4282-4296.

14. Meertens L, Carnec X, Lecoin MP, et al. The TIM and TAM families of phosphatidylserine receptors mediate dengue virus entry. Cell Host Microbe. 2012;12(4):544-557.

15. Sims B, Gu L, Krendelchtchikov A, Matthews QL. Neural stem cellderived exosomes mediate viral entry. Int J Nanomedicine. 2014;9: 4893-4897.

16. Sokolova V, Ludwig AK, Hornung S, et al. Characterisation of exosomes derived from human cells by nanoparticle tracking analysis and scanning electron microscopy. Colloids Surf B Biointerfaces. 2011;87(1): $146-150$.

17. Vlassov AV, Magdaleno S, Setterquist R, Conrad R. Exosomes: current knowledge of their composition, biological functions, and diagnostic and therapeutic potentials. Biochim Biophys Acta. 2012; 1820(7):940-948.

18. Hannafon BN, Ding WQ. Intercellular communication by exosome-derived microRNAs in cancer. Int J Mol Sci. 2013;14(7):14240-14269.

19. McDonald MK, Capasso KE, Ajit SK. Purification and microRNA profiling of exosomes derived from blood and culture media. J Vis Exp. 2013;76:e50294.

20. Feng D, Zhao WL, Ye YY, et al. Cellular internalization of exosomes occurs through phagocytosis. Traffic. 2010;11(5):675-687.

21. McLinden RJ, Labranche CC, Chenine AL, et al. Detection of HIV-1 neutralizing antibodies in a human CD4(+)/CXCR4(+)/CCR5(+) T-lymphoblastoid cell assay system. PLoS One. 2013;8(11):e 77756.

22. Sun J, Schaaf K, Duverger A, et al. Protein phosphatase, Mg2+/Mn2+dependent $1 \mathrm{~A}$ controls the innate antiviral and antibacterial response of macrophages during HIV-1 and Mycobacterium tuberculosis infection. Oncotarget. 2016;7(13):15394-15409.

23. Konadu KA, Chu J, Huang MB, et al. Association of cytokines with exosomes in the plasma of HIV-1-seropositive individuals. J Infect Dis. 2015;211(11):1712-1716.

24. Platt EJ, Kozak SL, Durnin JP, Hope TJ, Kabat D. Rapid dissociation of HIV-1 from cultured cells severely limits infectivity assays, causes the inactivation ascribed to entry inhibitors, and masks the inherently high level of infectivity of virions. J Virol. 2010;84(6): 3106-3110.

25. Li Y, Kappes JC, Conway JA, Price RW, Shaw GM, Hahn BH. Molecular characterization of human immunodeficiency virus type 1 cloned directly from uncultured human brain tissue: identification of replication-competent and -defective viral genomes. J Virol. 1991; 65(8):3973-3985.

26. Palma P. Human breast milk: is it the best milk to prevent HIV transmission? J Virus Erad. 2016;2(2):112-113.

27. Keller S, Rupp C, Stoeck A, et al. CD24 is a marker of exosomes secreted into urine and amniotic fluid. Kidney Int. 2007;72(9):1095-1102.

28. Pisitkun T, Shen RF, Knepper MA. Identification and proteomic profiling of exosomes in human urine. Proc Natl Acad Sci U S A. 2004; 101(36):13368-13373.

29. Andre F, Schartz NE, Movassagh M, et al. Malignant effusions and immunogenic tumour-derived exosomes. Lancet. 2002;360(9329): 295-305.

30. Admyre C, Johansson SM, Qazi KR, et al. Exosomes with immune modulatory features are present in human breast milk. J Immunol. 2007; 179(3):1969-1978.
31. Admyre C, Grunewald J, Thyberg J, et al. Exosomes with major histocompatibility complex class II and co-stimulatory molecules are present in human BAL fluid. Eur Respir J. 2003;22(4):578-583.

32. Street JM, Barran PE, Mackay CL, et al. Identification and proteomic profiling of exosomes in human cerebrospinal fluid. $J$ Transl Med. 2012;10:5.

33. Caby MP, Lankar D, Vincendeau-Scherrer C, Raposo G, Bonnerot C. Exosomal-like vesicles are present in human blood plasma. Int Immunol. 2005;17(7):879-887.

34. Michael A, Bajracharya SD, Yuen PS, et al. Exosomes from human saliva as a source of microRNA biomarkers. Oral Dis. 2010;16(1):34-38.

35. Sullivan R, Saez F, Girouard J, Frenette G. Role of exosomes in sperm maturation during the transit along the male reproductive tract. Blood Cells Mol Dis. 2005;35(1):1-10.

36. Chow YH, Yu D, Zhang JY, et al. gp120-Independent infection of CD4(-) epithelial cells and CD4(+) T-cells by HIV-1. J Acquir Immune Defic Syndr. 2002;30(1):1-8.

37. Marras D, Bruggeman LA, Gao F, et al. Replication and compartmentalization of HIV-1 in kidney epithelium of patients with HIV-associated nephropathy. Nat Med. 2002;8(5):522-526.

38. Mack M, Kleinschmidt A, Bruhl $\mathrm{H}$, et al. Transfer of the chemokine receptor CCR 5 between cells by membrane-derived microparticles: a mechanism for cellular human immunodeficiency virus 1 infection. Nat Med. 2000;6(7):769-775.

39. Arenaccio C, Anticoli S, Manfredi F, Chiozzini C, Olivetta E, Federico M. Latent HIV-1 is activated by exosomes from cells infected with either replication-competent or defective HIV-1. Retrovirology. 2015;12:87.

40. Rozmyslowicz T, Majka M, Kijowski J, et al. Platelet-and megakaryocytederived microparticles transfer CXCR4 receptor to CXCR4-null cells and make them susceptible to infection by X4-HIV. AIDS. 2003; 17(1):33-42.

41. Fang Y, Wu N, Gan X, Yan W, Morrell JC, Gould SJ. Higher-order oligomerization targets plasma membrane proteins and HIV gag to exosomes. PLoS Biol. 2007;5(6):e158.

42. Valadi H, Ekstrom K, Bossios A, Sjostrand M, Lee JJ, Lotvall JO. Exosome-mediated transfer of mRNAs and microRNAs is a novel mechanism of genetic exchange between cells. Nat Cell Biol. 2007;9(6):654-659.

43. Narayanan A, Iordanskiy S, Das R, et al. Exosomes derived from HIV1-infected cells contain trans-activation response element RNA.J Biol Chem. 2013;288(27):20014-20033.

44. Esser MT, Graham DR, Coren LV, et al. Differential incorporation of CD45, CD80 (B7-1), CD86 (B7-2), and major histocompatibility complex class I and II molecules into human immunodeficiency virus type 1 virions and microvesicles: implications for viral pathogenesis and immune regulation. $J$ Virol. 2001;75(13):6173-6182.

45. Khatua AK, Taylor HE, Hildreth JE, Popik W. Exosomes packaging APOBEC3G confer human immunodeficiency virus resistance to recipient cells. $J$ Virol. 2009;83(2):512-521.

46. de Carvalho JV, de Castro RO, da Silva EZ, et al. Nef neutralizes the ability of exosomes from CD4+ T cells to act as decoys during HIV-1 infection. PLoS One. 2014;9(11):e113691.

47. Li J, Wang Y, Wang X, et al. Immune activation of human brain microvascular endothelial cells inhibits HIV replication in macrophages. Blood. 2013;121(15):2934-2942.

48. Barr SD, Smiley JR, Bushman FD. The interferon response inhibits HIV particle production by induction of TRIM22. PLoS Pathog. 2008; 4(2):e1000007.

49. Bailer RT, Lee B, Montaner LJ. IL-13 and TNF-alpha inhibit dual-tropic HIV-1 in primary macrophages by reduction of surface expression of CD4, chemokine receptors CCR5, CXCR4 and post-entry viral gene expression. Eur J Immunol. 2000;30(5):1340-1349.

50. Creery D, Weiss W, Graziani-Bowering G, et al. Differential regulation of CXCR4 and CCR5 expression by interleukin (IL)-4 and IL-13 is associated with inhibition of chemotaxis and human immunodeficiency Virus (HIV) type 1 replication but not HIV entry into human monocytes. Viral Immunol. 2006;19(3):409-423. 
51. Requena M, Bouhlal H, Nasreddine N, et al. Inhibition of HIV-1 transmission in trans from dendritic cells to CD4+ T lymphocytes by natural antibodies to the CRD domain of DC-SIGN purified from breast milk and intravenous immunoglobulins. Immunology. 2008;123(4): 508-518.

52. Hong P, Ninonuevo MR, Lee B, Lebrilla C, Bode L. Human milk oligosaccharides reduce HIV-1-gp120 binding to dendritic cell-specific ICAM3-grabbing non-integrin (DC-SIGN). Br J Nutr. 2009;101(4): $482-486$.

53. Saeland E, de Jong MA, Nabatov AA, Kalay H, Geijtenbeek TB, van Kooyk Y. MUC1 in human milk blocks transmission of human immunodeficiency virus from dendritic cells to T cells. Mol Immunol. 2009;46(11-12):2309-2316.

54. Stax MJ, van Montfort T, Sprenger RR, et al. Mucin 6 in seminal plasma binds DC-SIGN and potently blocks dendritic cell mediated transfer of HIV-1 to CD4(+) T-lymphocytes. Virology. 2009;391(2):203-211.
55. Ruiz-Martinez M, Navarro A, Marrades RM, et al. YKT6 expression, exosome release, and survival in non-small cell lung cancer. Oncotarget. 2016;7(32):51515-51524.

56. Sigel K, Pitts R, Crothers K. Lung malignancies in HIV infection. Semin Respir Crit Care Med. 2016;37(2):267-276.

57. Van de Perre P, Simonon A, Hitimana DG, et al. Infective and antiinfective properties of breastmilk from HIV-1-infected women. Lancet. 1993;341(8850):914-918.

58. Datta P, Embree JE, Kreiss JK, et al. Mother-to-child transmission of human immunodeficiency virus type 1: report from the Nairobi Study. J Infect Dis. 1994;170(5):1134-1140.

59. Fowler MG, Newell ML. Breast-feeding and HIV-1 transmission in resource-limited settings. J Acquir Immune Defic Syndr. 2002;30(2): $230-239$. 


\section{Supplementary material}

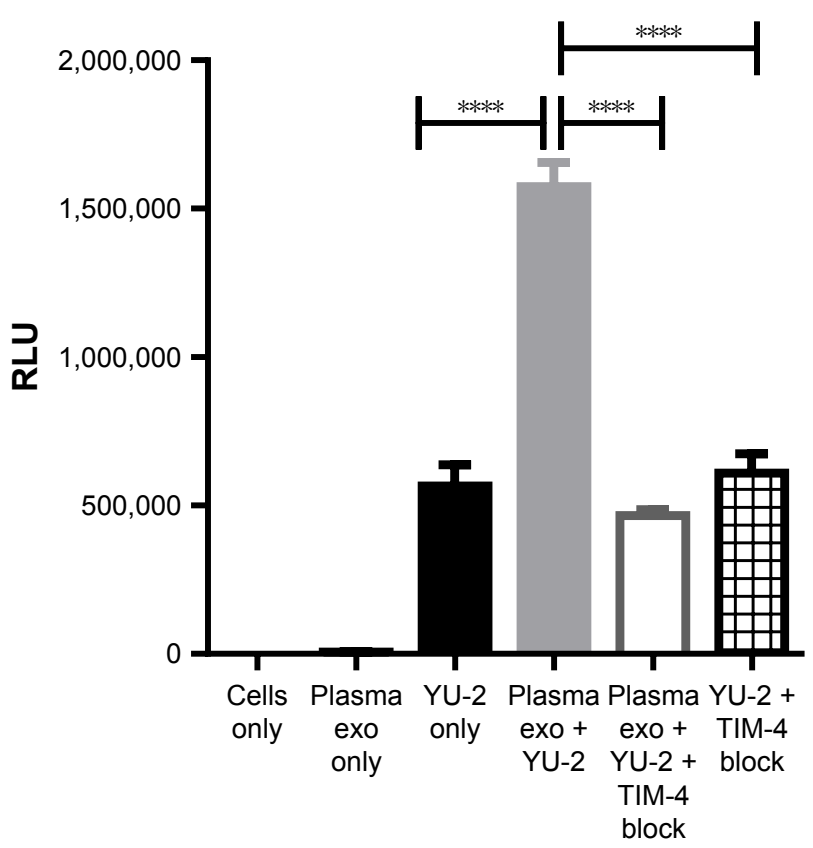

Figure SI Plasma-derived exosomes augment HIV-I entry in a monocyte/macrophage cell line.

Notes: The THP2574-derived macrophages were used for this entry experiments. YU-2 was used at an MOI of 0.18 . Virus entry was evaluated in the absence or presence of plasma-derived exosomes $(0.05 \mu \mathrm{g})$. Virus entry was evaluated in the presence or absence of exosomes, exosomes and TIM-4 antibody, and TIM-4 only, respectively. Cells only, exosomes only, YU-2 only, YU-2 + exosomes, YU-2 + exosomes + TIM-4 antibody, and YU-2 + TIM-4 antibody were analyzed by luciferase expression at $72 \mathrm{~h}$ post-infection. Data represent 12 independent experiments. Experimental significance was determined by one-way ANOVA $* * * * P<0.000$ I. YU-2, (NL-LucR.T2A-YU2.ecto) engineered to express Renilla luciferase (LucR) and ENV from the YU-2 virus strain.

Abbreviations: MOI, multiplicity of infection; TIM, T cell immunoglobulin and mucin; ANOVA, analysis of variance; RLU, relative luminescence unit; exo, exosomes.

International Journal of Nanomedicine

Dovepress

\section{Publish your work in this journal}

The International Journal of Nanomedicine is an international, peerreviewed journal focusing on the application of nanotechnology in diagnostics, therapeutics, and drug delivery systems throughout the biomedical field. This journal is indexed on PubMed Central, MedLine, CAS, SciSearch $®$, Current Contents $\AA /$ Clinical Medicine,
Journal Citation Reports/Science Edition, EMBase, Scopus and the Elsevier Bibliographic databases. The manuscript management system is completely online and includes a very quick and fair peer-review system, which is all easy to use. Visit http://www.dovepress.com/ testimonials.php to read real quotes from published authors.

\footnotetext{
Submit your manuscript here: http://www.dovepress.com/international-journal-of-nanomedicine-journal
} 